\title{
Tolerance as the Basis of the Polycultural Education Development
}

\author{
Tektibayeva Diana Dzhumabayevna ${ }^{1}$, Absatova Marfuga Absatovna ${ }^{2}$
}

\begin{abstract}
The aim of this article is to analyze psycho-pedagogical literature directed to present the problem of the tolerance as the basis of the polycultural education development. On the basis of this analysis the essence and the content of the "polycultural education" and "tolerance" concepts are presented. Thus, nowadays increases the role of the research of the national culture and value systems, conscious investigation of the specific features of various ethnoses, of valuable and symbolic aspects of national and ethnical societies' existence. In this regard Kazakhstani experience presents a special interest, as here representatives of numerous nations, ethnoses and confessions having ancient cultural customs and traditions dating back centuries are concentrated. Complex multi-level process of the formation of tolerance should be considered as a dynamic process of continuous acquisition of skills of peaceful, conflict-free coexistence in a polycultural, polyethnic and multiconfessional medium, based on the acceptance, respect and understanding of each other. Moreover, the characteristics of tolerance and its components are given in this article.
\end{abstract}

Keywords: polycultural education; polyethnic education; culture; tolerance; intolerance; ethnical tolerance.

\section{Introduction}

The development and perfection of polycultural personality, whose formation is only possible in the conditions of polycultural education, can lead to a qualitative change in the social conditions of life, to a new culture, affecting the society well-being. Under these conditions, increases the scientific and practical importance of the development of basic philosophical and ideological foundations, common principles, generally accepted norms of mutually respectful, peaceful and tolerant coexistence between civilizations, peoples, cultures and nations.

Maintenance of cultural identities, strengthening of ethnic identification, and maintenance of the diversity of existing civilizations becomes a vital need. (UNESCO International Programme "Culture of Peace", 2002) An effective way to solve the denoted governmental problem - is the manifestation of tolerance between different ethnic groups. This task is set by President of the Republic of Kazakhstan Nursultan Nazarbayev in his book "The Critical Decade" (Nazarbayev, 2005), focusing on this problem, as on the issue of national importance and as an indispensable condition of peace and harmony maintenance in polyethnic state (Nazarbayev, 2007).

That is why the development of tolerance is the objective requirement of contemporary society. In the conditions of the formation of new socio-economic relations, the problem of scientificallyproven adaptation of the educational system becomes of a special importance.

The acknowledgement to that is the Report of the International commission of UNESCO on global strategy of the development of education in the XXI-st century in which it is underlined, that one of the most important functions of school - is to teach people to live together, to help

${ }^{1} 3^{\text {rd }}$ Year PhD Candidate, Department of Psycho-Pedagogical Specialties at Kazakh National Pedagogical University Named after Abai, Almaty

2 Doctor of Pedagogical Sciences, Professor at the Department of the Psycho-Pedagogical Specialties at Kazakh

National Pedagogical University named after Abai, Almaty. 
them to transform existing interdependence of states and ethnoses to the conscious solidarity. For these purposes education should promote, on the one hand, the personal realization of his/her roots and, thereby, the definition of a place he/she occupies in the world, and on the other hand - to instill him/her the respect to other cultures ("Education: the Hidden Treasure", 1997).

Thus, in the conditions of the sustainable development of the cultures diversity and their interrelation to the society the problem of the polycultural education and the formation of the students' tolerant attitude towards the representatives of the various cultures and ethnoses is crucially actualized.

\section{Main Part}

As a multi-ethnic and multi-confessional state, Kazakhstan has a vast opportunities and wealth represented by the population. In our country, no one socially significant process can be without the interaction of different nationalities and religions. In Kazakhstan, there was founded a unique by its significance institution, as the Assembly of people of Kazakhstan.

According to the National Unity Doctrine published by Assembly of people of Kazakhstan it is stated that "wisdom and tolerance of the people served as a unifying element for the consolidation of all the citizens of the new state, regardless of ethnic origin, social, religious or other affiliation. In the most difficult years of independence formation, thanks to the wisdom of the People and the policy of the first President of the country - Nursultan Nazarbayev, Kazakhstan has managed to avoid inter-ethnic clashes and division of society. Thereat, in terms of overcoming the post-Soviet crisis, building a new economic and political relations, social consolidation was achieved on the basis of the enunciated principle of internal political stability, civil peace and interethnic harmony. "Unity in diversity" has become our common heritage, and agreement between peoples - our greatest achievement, a symbol of Kazakhstan, the guarantee and the basis for successful socio-economic and socio-political development of the country.". The National Unity Doctrine states the principles of National Unity of Kazakhstan as follows: I.«One Country - One Destiny», II. «Different Origin - Equal Opportunities», III. «Development of the National Spirit». These principles serve as the directories for the further national consolidation (National Unity Doctrine, http://www.assembly.kz/).

Kazakhstan has initiated a resolution of the General Conference of UNESCO's proclamation of the International Decade for the Rapprochement of Cultures from 2013 to 2022, co-sponsored by 27 countries - members of the organization, which shows the image of our country in the world, in the light of the creation of favorable conditions and implementation of the dialogue of cultures. The formation of our country as the platform for dialogue and global integration center becomes evident from the fact that international events as - Eurasian Media Forum, Astana Economic Forum, the Congress of Leaders of World and Traditional Religions and others, are held in Kazakhstan. It should be noted that a virtual platform for dialogue - "G-Global" has been created in Kazakhstan; it is designed to be a platform for dialogue with the international community to address, discuss and solve global issues. All the above mentioned is an obvious fact, confirming the need of the introduction to the educational practice of questions concerning formation and development of students' abilities to co-exist as a united population, and of detailed consideration of problems concerning the conditions and the possibility to realize student's personality self-development in the context of the tolerance development in the conditions of polycultural education.

The analysis of the literature on the studied problem shows that the history of the development of pedagogical culture of the Kazakh people goes back centuries (Zharikbaev et al., 1995). Over the long period of history the inhabitants of the vast steppes have accumulated rich experience in the education of future generations, created the customs and traditions that combine creativity of the 
masses, rules, norms and principles of human behavior. According to peculiar features of socioeconomic, cultural-historical, natural and climatic conditions the national character and requirements for training and education of children and youth have formed among Kazakh nomads. We referred to the fact that was written on this occasion by S. Temirbekov "National character - is the qualities and characteristics of the people, reflecting their specific features and manifesting in their behavior, actions and deeds, in their tastes and preferences, manners and speech, even in the character of a conversation and gestures, in their relations with each other and with other nations" (Temirbekov, 1999).

Consequently, S. Temirbekov points such a fundamental value of people in their national character that comes basic in their mentality as well.

By the end of the twentieth century, the idea of the interpenetration of different cultures, multiethnic diversity of our country, the formation of polycultural personality was developed by such Kazakh scientists as K.B. Zharikbaev, S.K. Kaliev, Zh.Zh. Nauryzbay, S.A. Uzakbayeva, A.A. Beysenbayeva, R.T. Abdullatipov and others (Temirbekov, 1999; Kaliev, 1990; Nauryzbay, 1997; Uzakbaeva et al., 1996; Beysenbaeva, 1998).

Many philosophical aspects of the formation of humanistic type of thinking and problems of correlation of consciousness, sense, language, collectivity of humanistic and social spheres, with all the general interconnections between them are represented in the works of the philosopher A. Nysanbaev (Nysanbaev, 2001) in a new and accessible manner. In this works the live speech is represented as an important instrument for the development of sense, consciousness, thinking and creative abilities of people, primarily children of pre-school and school age.

It is noteworthy that in the works of A.A. Beysenbaeva the convergence of cultures is declared; justified by the personal-activity approach to the humanization of education through culture as a set of universal and national values. The scientist points out that "in the integral pedagogical process at school there should be a penetration of various cultures without missing of any opportunity to enrich the spiritual world of students by all the achievements of every people" (Beysenbaeva, 1998).

Polycultural education - is a process of studying by the younger generation of ethnic, national and world culture aiming the spiritual enrichment, the development of globalization and global consciousness, the formation of readiness and ability to live in a multicultural polyethnic medium presented by the system of cultural values, differing from the own ones. The perspectives of upbringing of personal qualities of a culture man, a citizen of the world, are connected with the polycultural education (Absatova et al., 2013). From this definition comes the conclusion that nothing but the tolerant attitude or tolerance, should be considered as the basis of polycultural education, as it acts as the mechanism of readiness and ability to live in polycultural and polyethnic medium.

The solution of the problems of students' polycultural education requires an intensification of polycultural component in the training of future teachers. In this regard, a theoretical position of multiculturalism as an important component of professionalism proposed by Dmitriev gains a certain importance (Absatova et al., 2013). On the basis of this position, students studying at various specialties, particularly pedagogical ones, "must be able to work with people of various cultures, to understand appropriately differences between people, to be tolerant to them, to be able to assert cultural pluralism in society by means of personal affairs and words" (Makaev et al., 1999).

In the dictionary of conflictologist the following definition is provided: tolerance (from lat. tolerante - patience) is the absence or weakening of the response to any conflict-factor. Internally appears as the increase of the threshold of emotional response to the conflict situation, and externally - in the moderation and self-control. Tolerance - is one of the basic psychological conditions of conflict prevention (Antsupov et al., 2010). From this point of view, it becomes 
obvious that tolerance is the factor that lays in the basis of conflict resolution, for its avoiding and prevention.

The essence of tolerance is given more completely in the "Declaration of Principles on Tolerance", adopted in 1995 by the United Nations Educational, Scientific and Cultural Organization. As stated in the Declaration (Article 1), "Tolerance means respect, acceptance and appreciation of the rich diversity of our world's cultures, our forms of self-expression and ways of human individuality expression. Tolerance - is a harmony in diversity. Tolerance - is not a concession, condescension or indulgence. Tolerance - is, first of all, an active attitude prompted by the recognition of the universal human rights and fundamental freedoms. Tolerance - is the notion denoting the rejection of dogmatism and absolutism of the truth and affirming the standards set out in international legal acts in the field of human rights. The manifestation of tolerance, which is accordant with respect of human rights, does not mean toleration of social injustice or the abandonment (or acquiescence) of the own convictions and accepts the same right of the others. It also means that one's views cannot be imposed on others" (UNESCO Declaration of Principles on Tolerance, 2001).

As a consequence, tolerance suggests that, on the one hand, subjects of interaction retain their independence and autonomy, and on the other - they do not have to limit the freedom of others, understanding and defining their identity and self-worth, respecting their right to choose, the right to be different in their views, interests, habits, beliefs, which at the same time should not confront the idea of tolerance itself.

The following criterions of tolerance are pointed out: equality (equal access to social benefits, to administrative, educational and economic opportunities for all people, regardless of their gender, race, nationality, religion, membership in any other group); mutual respect of group or society members, benevolence and tolerance to different groups (people with disabilities, refugees, people from sexual minorities, etc.); all society members' equal opportunities to participate in the political life; the preservation and development of cultural originality and languages of national minorities; the coverage by the events of public nature, by the holidays as many people as possible, if it is not against their cultural traditions and religious beliefs; the ability to follow their own traditions for all cultures represented in society; freedom of religion, provided that this does not prejudice the rights and opportunities of other members of society; cooperation and solidarity in solving common problems; positive lexis in the most vulnerable spheres of inter-ethnic, inter-racial relations, in gender relations.

In addition, four main components of tolerance are defined as follows: the recognition, acceptance, respect and understanding. Acceptance and recognition of the differences existing between people today can be considered as the most appropriate form of cross-cultural interaction. In the explanatory dictionary of V.Dal "recognize" means "to recognize, as to take for the truth, to confirm, to accept as the opinion, belief, to realize". In turn, "accept" - "to take in respect, in attention or to honor, agree; to listen, to believe, to recognize as the cause" (Dal, 1980). From the humanistic positions, the acceptance of another one as he/she is means the original orientation on the person and his value as a personality, a willingness to interact with a person, the recognition of his rights to personal interests, consideration of his peculiarities, the assumption of his/her possible acrid difference from the rest. "Accept" - means to entrust, to admit as much as possible into the own inner world and relate your own behavior and interests with the interests and behavior of another person. Acceptance of a person, according to S.L. Rubinstein, means the assertion of the original existence of exactly this man, with all of his/her inherent qualities. It is a rejection of the assessments of his/her personality, but unconditional attitude towards him/her (Rubinstein, 1957).

Analyzing these definitions, it can be concluded that during the education the trainee should acquire and develop the quality of tolerant and friendly attitude, emotional familiarity and 
empathy in relation to the whole environment/medium, regardless of ethnic, national or other social affiliation, that is, to acquire and to develop tolerance.

Training of the tolerance, above all, solves the problem of disclosure of the sense of human-being existence in the world through the understanding of the nature and methods of his/her interaction with the world. The process of education and upbringing in a tolerant medium comes through the process of conceptualization of one's place in the world that has multidimensional and polycultural character, in the mastering of ways of interaction with it. Ultimately, the discussion is about the perception of tolerance as a personally-significant value that can be developed in polycultural medium.

Problem of tolerance is a subject of investigation of philosophy, sociology, psychology, ethnography, history, religion studies, culture studies and other disciplines. In pedagogy, it has gained prominence in the last decade in terms of humanistic education. For the history of pedagogy the idea of tolerance is not entirely new.

Found on the researches of L.M. Drobizheva, G.U. Soldatova the typology of tolerant relations in the system of individuum-group was created:

1) Active tolerance (transparency, a willingness to inter-ethnic contacts);

2) Passive tolerance (irregular inter-ethnic contacts, the tendency to communicate with the representatives of their nationality, while maintaining a positive attitude towards the representatives of foreign-ethnic groups);

3) Elective tolerance (interethnic contacts are limited because of different grounds - language, religion, cultural characteristics);

4) Forced tolerance (ethnic contacts occur under pressure and are only of business character, for example, the career topic);

5) Intolerance (categorical unwillingness to interact with people of other cultures). (Soldatov et al., 2001)

According to the works of the psychologists of the scientific-practical centre "Gratis" and of the Centre of Tolerance and Humanitarian Technologies founded on the Chair of personality psychology at the Faculty of Psychology at Moscow State University the following aspects of tolerance were distinguished: ethnic tolerance, social tolerance, tolerance as a personality trait.

Investigation of the ethnic tolerance allows to educe personal relation to other ethnic groups and attitudes in intercultural interaction. For the formation of civil society we need to educate a citizen - a person who has relevant to the society orientation values. One of the most important qualities of such a person is ethnic tolerance - the ability to tolerate, and most importantly - to be sensitive to people of other nationalities, their customs, traditions, culture, patterns of behavior, way of life. Ethnic tolerance, or, on the contrary, ethnic intolerance largely determines the nature of international relations.

Studying of the social tolerance allows to explore tolerant and intolerant acts towards the various social groups (minorities, criminals, mentally sick persons), and to investigate personal attitudes towards some social processes. Social tolerance is also represented by inter-individual and intersocial forms. Social tolerance - is a form of partner interaction between different social groups in society, its structures of authority, when the need for such cooperation and respect to the positions of the parties are approved. It is directed to the equality in society and recognizes the right of people to cooperate in order to protect their rights and interests. In the socially oriented society the conditions for the formation of personal tolerant consciousness, responsibility, including legal responsibility are created.

Investigation of the tolerance as a personal trait allows to diagnose personality traits, attitudes and views that vastly determine the person's relation to the world. Tolerance as a character trait means the respectful treatment to people, a priori. This kind of respect is applicable to a variety of lifestyles. Some people carry a charge of love and good will. Others appreciate group differences 
from the aesthetic point of view and find them interesting and challenging. For the third ones tolerance stays as a part of the political liberalism and progressive philosophy. For the fourth ones the most important is a sense of justice. For the rest, the treatment to the different groups is associated with the concept of international friendship. They realize that peaceful relations between the representatives of all races are not possible until "colored" people are treated differently in their homeland. In other words, tolerance as a trait of character is interwoven into a positive view on the world.

Genuine tolerance is a valuable moral quality of a mature person, i.e. a person who has his/her own values and interests and is ready, if necessary, to protect them, but at the same time respects the beliefs and values of others. In another words, a person, who does not need humiliation or destruction of someone else for self-affirmation. Tolerance involves the realization of the fact that the World and social environment are multi-dimensional, and, thus, the views on this world are diverse and cannot, and must not be reduced to uniformity, or in someone's favor. It means that any forms of preferences, privilege for certain social, ethnic, cultural, and other groups and the oppressions of others are not allowed. At the same time, tolerance requires preservation of the natural, healthy dislike of the negative phenomena in terms of ideology, communication and behavior. Tolerance is not identical to the lack of evaluations, to indifference in moral trend of ideological worldview orientation. It also does not mean indulgence, reconciliation with morally blameworthy phenomena. Thus, tolerance in the social aspect - is patience to other people's opinions, beliefs and behaviors, to other people's critics of their own actions; in the psychological aspect - it is the ability to maintain psycho-emotional stability and adequate response to the events and phenomena in the conditions of various types of disturbance. The modern concept of the tolerance essence is based on the recognition, acceptance, understanding and respect of the otherness, difference, and the willingness to a dialogue.

Thus, tolerance is a moral quality that characterizes the attitude to the interests, convictions, beliefs, habits and behavior of other people, that is expressed in an effort to reach mutual understanding and agreement in diverse interests without application of pressure, mainly by means of explanation and persuasion methods; at the same time the formation of tolerance is a complex multi-leveled process involving intellectual, emotional, motivational and volitional sphere of self-regulation, subject-practical and existential sphere of human consciousness, which derive their development in the period of adolescence, which coincides with the period of studying at the university. This process should be considered as a dynamic process of continuous acquisition of skills of peaceful, conflict-free coexistence in a polycultural, polyethnic and multi-confessional medium, based on the acceptance, respect and understanding of each other.

\section{Conclusion}

Contemporary socio-cultural situation defined the crucial necessity in the formation of tolerance as a condition of future humanity survival in polycultural and polyethnic society; as a value of socio-cultural system; as humane regulations of human relationships; as worldview and conscious roadmap to the construction of interrelations with the world. At the same time polyethnic medium should not be considered as a 'melting pot', because generally a human not only saves the devotion to his/her own basic ethnical culture, but also can combine the appurtenance to the several cultures. Cultural changes that are the consequences of polyethnicity and polycultural character of a medium bring only to the universalization of the personal characteristics. This allows esteeming the tolerance as the multicomponent phenomenon of objective reality, with the essence that is difficult to overvalue. 


\section{References}

UNESCO International Programme "Culture of Peace". Moscow, 2002.

Nazarbayev N.A. 2005. The Critical Decade. Astana, pp: 485.

Nazarbayev N.A. New Kazakhstan in a New World: Address of the President of the Republic of Kazakhstan Nursultan Nazarbayev to the people of Kazakhstan. Almaty, 2007.

Education: the Hidden Treasure: The report of the International Commission on the Education for the XXI Century: UNESCO. Paris, 1997.

National Unity Doctrine. Retrieved from http://www.assembly.kz/ru/docs/doktrina-nacionalnogo-edinstva Zharikbaev K.B., S.K. Kaliev, 1995. Anthology of pedagogical intention in Kazakhstan. Almaty, pp: 512.

Temirbekov S.T., 1999. About one fundamental value. Thought, 7: 24-26.

Kaliev S.K., 1990. Pedagogical thoughts and beliefs in poetry of Akyns and Zhyraus. Almaty, pp: 88.

Nauryzbay Zh.Zh., 1997. Scientific and pedagogical foundations of ethno-cultural students' education. Doctor dissertation thesis (autoabstract), Almaty, doctor ped. sciences.

Uzakbaeva S.A., K.Zh. Kozhakhmetova, 1996. Application of Kazakh ethno-pedagogics materials in studying pedagogical subjects. Almaty, pp: 34 .

Beysenbaeva A.A., 1998. Theory and practice of the school education humanization. Almaty: Gylym, pp: 225.

Nysanbaev A.N., 2001. Philosophy. Almaty, pp: 253.

Absatova M., T. Nurpeisova, D. Tektibayeva and L. Mamytbekova, 2013. Scientific-theoretical basis of polycultural education development in polyethnic medium. World Applied Sciences Journal, 23 (10): pp. 1360-1365. ISSN 1818-4952

Makaev V.V., Z.A. Malkova, L. Suprunova, 1999. Polycultural education - the actual problem of the modern school. Pedagogics, 4: 3-10.

Antsupov A.Ya., A.I. Shipilov, 2010. The dictionary of conflictologist. Moscow: Eksmo, pp: 656.

UNESCO Declaration of Principles on Tolerance. Moscow, 2001.

Dal V.I., 1980. Explanatory Dictionary of the Russian Language. Volume 3. Moscow, pp: 555.

Rubinstein S.L., 1957. Being and consciousness. Moscow.

Soldatov G.U., L.A. Shaygerova, O.D. Sharov, 2001. Living in peace with ourselves and others. Tolerance training for teens. Moscow. 
